\title{
Hints of bone bounties rile fossil hunters
}

Rex Dalton, Denver

Claims that researchers may have paid tribesmen in Eritrea monetary bounties for fossils and ancient stone tools surfaced at the annual meeting of the Paleoanthropology Society this month.

The allegations concern an extremely valuable fossil site in an isolated area of the East African state, near the village of Buia. It was in this region, known as the Danakil Depression, that an Italian-led team in 1995 found clues of early hominids, including a skull (see E. Abbate et al. Nature 393, 458-460; 1998).

The introduction of bounty payments to a virgin exploration area would have a significantly adverse impact, anthropologists say. When impoverished local residents learn that they can make money by selling artefacts, scavenging can destroy palaeontology sites and make specimen dating more difficult. This has already occurred elsewhere in Africa, in China and in South America.

On 19 March, Lorenzo Rook of the University of Florence told the meeting in Denver, Colorado, that when his team returned to the Buia site in January this year, local tribesmen appeared at the camp offering fossils and stone tools for sale. In previous trips to the region, no tribesman was known to have engaged in this practice, Rook said.

Questioned through translators, the tribesmen said that they had been offered "dollars" by recent explorers, Rook claimed, adding that the tribesmen had also learned a few English-language phrases.

About three months previously, another research team had spent several weeks surveying the Buia region during a contentious research trip (see Nature 415, 463; 2002). That team, led by anatomist Randall Susman of Stony Brook University in New York, and including geologist Roger Smith of the South African Museum in Cape Town, covered territory that Rook's team had previously worked on.

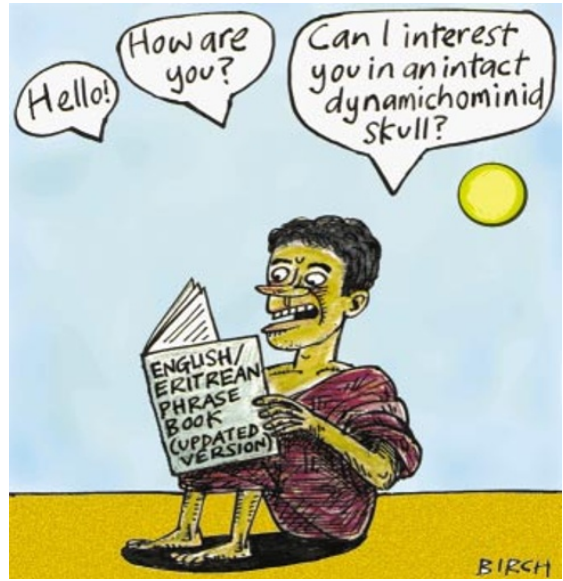

In January, Eritrean antiquities officials cancelled Susman's permit to conduct research at the Buia site. In a letter, the officials said that Susman should not have worked in the Italians' area, and that he failed to notify the government of Smith's presence on the team and had no authorization to collect fossils and stone tools. The specimens recovered by Susman's team were deposited at the National Museum of Eritrea.

In an interview, Susman emphatically denied paying any bounties to tribesmen for collecting specimens. Such an allegation is "absolutely, utterly false", he says. Smith also denies paying anyone for fossils or tools.

Rook, who eventually obtained an exclusive permit to explore the Buia area after antiquities officials became upset with Susman's activities, says he has filed a verbal report with Eritrean officials about the bounty issue. The officials could not be reached for comment.

Susman, who has explored African sites for 25 years, says he has given up trying to conduct research in Eritrea. Calling the Eritrean actions "a kangaroo court", Susman says: "I'm done there. It was a morass - a failure waiting to happen. The Italians can have the joy of me being thrown out."

\section{Babies' cancer screens 'not needed'}

\section{Alison Abbott, Munich}

Screening for cancer seems to be ineffective in saving the lives of babies with nerve tumours, concludes a pilot study of some 1.5 million children in Germany.

The babies were screened for neuroblastomas, the second most common tumour found in children. But the results have raised worries that some toddlers may have been put through gruelling treatment - usually involving surgery and chemotherapy - to remove tumours that might have gone away of their own accord.

The results of the study were presented as abstracts at the Congress of the German Cancer Society in Berlin earlier this month, and will be published in April in an international clinical journal.

Coming hot on the heels of last October's assessment of mammography by the Nordic Cochrane Centre in Copenhagen which raised similar questions about the effectiveness of mass screening for breast cancer - the study is likely to spark fresh debate on cancer-treatment policy.

Neuroblastomas are responsible for the deaths of 15 in every 100,000 children. Chances of survival are improved if the condition is caught early, and the cancer has particular properties that make early diagnosis relatively easy - most tumours produce chemicals called catecholamines, the breakdown products of which can be detected in urine.

The German screening programme was introduced in 1995 with the financial support of Deutsche Krebshilfe, a German cancer charity, and health insurance companies. The parents of about 1.5 million one-year-olds delivered nappies, for urine extraction, to participating clinics in six German states.

The screen identified around 150 cases of

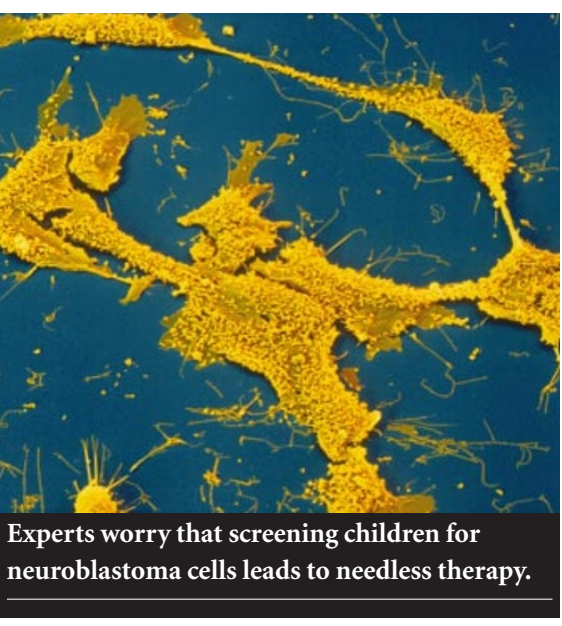

neuroblastoma, but missed a further 55 cases, which were later discovered in advanced stages of development. The detection of so many early cancers has not, as yet, reduced the number of deaths from neuroblastoma compared with a control group of unscreened children.

Freimut Schilling, an oncologist at the Olgahospital in Stuttgart, one of the clinics participating in the study, notes that "a considerable number of children may undergo unnecessary treatment on a spontaneously regressing tumour as considerable overdiagnosis was observed".

Schilling wrote in his abstract that mass screening for neuroblastoma "cannot be recommended as a general health measure". The authors of the study and officials at the Deutsche Krebshilfe are declining to comment further on the results in advance of their publication - as are scientists participating in the Quebec Neuroblastoma Screening Project, a similar, but smaller, screen in North America that has reportedly obtained similar results. 